\title{
Stem Cell Interventions for Bone Healing: Fractures and Osteoporosis.
}

\author{
Anita Sanghani-Kerai ${ }^{1 *}$, Dara McCreary ${ }^{1}$, Henry Lancashire ${ }^{1}$, Liza Osagie ${ }^{1}$, Melanie Coathup ${ }^{1}$, Gordon Blunn². \\ 1. Institute of Orthopaedics and Musculoskeletal Science. Division of Surgery and Interventional Sciences. \\ University College London, Stanmore, London. HA7 4LP, UK \\ 2. University of Portsmouth. School of Pharmacy and BMC. White Swan Road. Portsmouth. PO1 2DT, UK
}

* Address correspondence to this author at the Department of Materials and Tissue. Institute of Orthopaedics and Musculoskeletal Science. Division of Surgery and Interventional Sciences. University College London, Royal National Orthopaedic Hospital, Stanmore, Middlesex HA7 4LP, UK. Tel: 07784604432. Fax: 02084207392. Email:a.sanghani.12@ucl.ac.uk

\section{* Abstract}

* With the ageing population, musculoskeletal conditions are becoming more inherent. Delayed union is defined as a slower than normal fracture healing response, with no healing after 4 to 6 months; however, union is anticipated given sufficient time. In the context of delayed/non-union, fragility fractures in osteoporotic populations carry significant patient morbidity and socioeconomic costs. Multiple mechanisms hinder fracture healing in osteoporotic patients, imbalanced bone remodelling leads to impaired bone microarchitecture due to reduced osteoblast number and activity and as such, callus formation is diminished. Since stem cells can self-renew and differentiate into various tissue lineages, they are becoming very popular in tissue regeneration in musculoskeletal conditions. In this review we discuss the role of stem cells in physiological fracture healing and their potential therapeutic use following a fracture. We explore the potential of stem cells, the release of chemokines and cytokines to reduce fracture risk in osteoporosis.

$*$

$*$

* Keywords: stem cells; Fracture; osteoporosis; bone; healing; regeneration

\section{Introduction}

Over $\$ 2.5$ billion is spent on an estimated 3 million musculoskeletal procedures in the United States of America with 7.9 million bone fractures reported annually [1,2]. Worldwide reported hip fracture rates per 100,000 of the population are 400.7 (52.1 to 920.7) for women and 147.8 (37 to 567) for men (median and range), with an 
increasing elderly population these are predicted to rise. Fracture healing typically occurs after a period of immobilisation or surgical reduction in approximately $90 \%$ of cases. Yet in $5-10 \%$ of cases, radiographic union is not achieved within 6 months, thus termed a "delayed" or possible "non"-union. Subsequently, the fracture gap may be filled with fibrous callus that necessitates intervention $[2,3]$.

Delayed union is defined as a slower than normal fracture healing response, with no healing after 4 to 6 months; however, union is anticipated given sufficient time. Non-union is diagnosed when no bony fracture healing is observed over a longer time period, typically 9 months, and no radiographic progression is observed for 3 consecutive months [4-7]. Aseptic non-unions are defined as either hypertrophic or atrophic: hypertrophic nonunions occur due to inadequate immobilization, they demonstrate significant local bone formation and a well vascularised callus, with an upregulation of type II collagen production. Atrophic non-unions have little or no new bone formation at the fracture site and are associated with biological or mechanobiological impairment of osteogenesis $[4,7]$.

In the context of delayed/non-union, fragility fractures in osteoporotic populations carry significant patient morbidity and socioeconomic costs. Currently 10 million people in the United States have osteoporosis, with a resulting significant impact on fracture numbers, and ultimately the incidence of non-union [8]. Multiple mechanisms hinder fracture healing in osteoporotic patients, imbalanced bone remodelling leads to impaired bone microarchitecture due to reduced osteoblast number and activity and as such, callus formation is diminished. Secondly, structural incompetence inherent in osteoporotic bone hinders osteosynthesis, with failure rates of some fracture fixation techniques as high as $50 \%$. Subsequently, the clinical need remains to identify biologics and/or biomaterials that can be economically viable adjuncts to fracture healing in all patient populations [9-12].

This review discusses regenerative medicine and biomaterial interventions to improve fracture healing. First we focus on the role of stem cells in physiological fracture healing and their potential therapeutic use following a fracture. We explore the potential of stem cells to reduce fracture risk in osteoporosis in stem cell regenerative treatment.

\section{Fracture healing}

\subsection{Role of stem cells in fracture healing}

Following a fracture, bone has the capability of self-repair and regeneration. There are multiple factors, which regulate the cascade of events involved in fracture healing; understanding the cellular and molecular pathways during healing is critical for determining the fracture treatment in cases with poor prognosis. This complex biological event involves both intracellular and extracellular pathways of bone induction and the coordination of several cells types including stem cells $[13,14]$.

Fractures heal through different pathways, determined predominantly by the biology and mechanical stability at the fracture site $[15,16]$. In conditions of "absolute stability" typically where fractures are reduced and surgically fixed, bones can heal by direct bone repair. Indirect bone repair is where endochondral ossification occurs to bridge a gap at the bone ends. In both processes, strain drives the differentiation of mesenchymal stem cells. If the bone is stable, but slowly distracted (lengthened) to maintain a gap, callotaxis (distraction osteogenesis) can take place. Rather than a repair mode callotaxis is often used as an intervention for bone growth and treatment of skeletal anomalies [17].

Direct bone repair, occurs through a combination of gap and contact healing, where the fracture site is rigidly stable. In this case healing occurs in a manner similar to normal bone remodelling: no cartilage callus forms and the bone repair is supported by the existing bone. Osteoclast cutting cones resorb bone immediately adjacent to [18]the fracture site, followed by osteoblasts, which synthesise new lamellar matrix [3, 15]. If there is a small gap which is stable, healing follows a similar pathway, without the formation of a cartilage callus. Fibrous tissue forms within the gap, which is invaded by mesenchymal stem cells. Woven bone is synthesised at the edges of the gap and proceeds to fill the gap. Simultaneously, new bone at the fracture edges is remodelled to form lamellar bone perpendicular to the normal bone axis. Subsequently these structures are remodelled to align with the long axis of the bone in a normal cortical structure $[15,16]$. 
If the fracture gap is less stable, endochondral bone repair can take place. This indirect or secondary bone healing is of particular interest as it is the more common healing model [16]. The first stage of endochondral repair overlaps with the formation of a fracture haematoma and an inflammatory response. Blood clots are observable within hours following fracture, and form a fibrin scaffold, which bridges the fracture creating a matrix for the invasion of repairing cells $[19,20]$. Simultaneously inflammatory cells, platelets and the bone extracellular matrix (ECM) release factors that are responsible for the migration of stem cells to the injury site and subsequent differentiation $[21,22]$. Subsequently endochondral fracture healing is similar to normal bone development, which occurs through endochondral ossification [18,23]. Depending on the stability of the fracture, a cartilaginous soft callus forms. First, the fibrin clot is remodelled, stem cells differentiate along a fibroblastic lineage and secrete collagen to form an early fibrous callus within the first few days after fracture [19]. Angiogenesis then occurs allowing circulating cells to migrate rapidly to the fracture site [24]. Stem cells differentiate to chondrocytes which further remodel to form a cartilaginous callus.

Fracture healing is not an isolated event; the process includes various factors that act in synergy and this affects the homing and promotion of cells. The dose of these factors will have knock on effects on the therapeutic treatments they are involved in. BMP-2, vascular endothelial growth factor (VEGF) and Fibroblast growth factor (FGF) are all dose and time dependent leading to osteogenic differentiation of MSCs [25]. Bai et al (2013) have shown that low concentrations of these factors will have more of a positive effect on MSCs [26]. Multiple factors play varying roles in the cascade of MSCs which shows MSCs are not only controlled by both chemotactic and mechanical factors [27, 28]. Additionally, local cells also contribute to the healing process. Committed osteoprogenitor cells of the periosteum and undifferentiated multipotent MSCs are initially activated. Local and systemic regulatory factors such as VEGF, FGF, Insulin-like growth factor (IGF), TGF $\beta$, various cytokines and hormones interact with these localised cells to attract more cells to the region and initiate the healing process [29, 30].

Cellular recruitment occurs mainly from local tissues. In direct bone healing, the primary source being the bone marrow of the fractured bone [31]. However, during secondary bone healing, stem cells derived from the periosteum are mainly responsible for chondrogenesis [31, 32]. In addition muscle can provide a source for prechondrocytes which differentiate from satellite cells (16). Therefore, to ensure bone healing, any surgical procedures should avoid further damage to the periosteum and overlying muscle [23]. The third stage involves the formation of a hard callus of primary bone, on a stable mineralised surface (e.g. existing bone). Primary, osteoblastic differentiated mesenchymal cells from the periosteum, endochondral bone and bone marrow, synthesize a scaffold of woven bone $[15,21,31]$. The final stage involves remodelling of immature bone into organised lamellar bone with a trabecular structure.

Bone healing is controlled by the interaction of regulatory factors, such as cytokines and hormones; osteoconductive matrices or scaffolds, mechano-biology or relative mechanical stability of the fracture site, a population of stem cells and a blood supply [21,29]. Multiple cell types are involved in fracture healing, including osteoblasts, osteoclasts, osteocytes, osteoprogenitors and most importantly stem cells, which act in response to both mechanical signalling and the biochemical signalling cascade [33]. The sources of stem cells during fracture healing include bone marrow derived mesenchymal stem cells (bMSCs) and periosteum derived mesenchymal progenitor cells (PDCs). There is some evidence for contributions made from endothelial progenitor cells (EPCs), muscle derived stem cells and perivascular stem cells (PSCs) [23, 34-42].

\subsection{Tissue biomechanics in stem cell activation and differentiation}

Stem cells are sensitive to local tissue microenvironments. Inherent properties of the materials surrounding cells include stiffness, degradability, adhesion, chemical moeties, and nanotopography. In addition, the local mechanical environment can induce and alter stem cell differentiation and subsequently tissue formation [43-46]. Tissue strain affects the type of bone formed, with rigid fixation leading to mainly intramembranous repair, while compliant fixation leads to healing predominated by endochondral bone repair [47].

\subsection{Stem cells in pre-clinical and clinical studies of fracture healing}

When the recruitment of autogenic cells for bone repair is impaired such as in a comminuted fracture or where the blood supply is compromised, a delayed or non-union may occur. In these situations, delivering stem cells to 
the fracture site has the potential to enhance bone repair [41, 48, 49]. Based on the original work of Friedenstein [1], some studies have reported positive outcomes following ex vivo expansion of harvested bone marrow cells. Therefore, progenitor cells in the order of millions can be expanded from bone marrow and later re-implanted within the fracture site. A number of clinical trials have investigated the use of expanded autologous stem cells to enhance fracture healing with varying degrees of success [50, 51].

The vast majority of pre-clinical studies have investigated the use of implanted bone marrow derived stem cells, though a growing body of work is exploring the use of adipose derived stem cells [52, 53]. Studies have suggested superior cell yield (6-fold), differentiation capacity and immunomodulation of adipose derived cells compared with those obtained from bone marrow, hence increasing interest in their use in bone healing and repair [54] . Subsequently, canine and murine studies have demonstrated the efficacy of allogenic adipose derived cells in the healing of long bone and cavarial defects, although few studies have shown autologous adipose derived cells to improve bone formation in clinical studies [55-59].

A number of studies have investigated the administration of a mixed population of progenitor cells, which include mesenchymal stem cells, endothelial progenitor cells (EPCs) and haematopoeitic stem cells. EPCs are a valued resource as they contribute to the formation of vascularised tissue. When EPCs are co-implanted with stem cells and supplemented with VEGF, a more mature vascularised bone tissue has been shown to form in the fracture $[36,60-63]$.

Small scale trials have reported enhanced fracture healing, reduced morbidity and reduced disease progression with the use of ex vivo expanded mesenchymal stem cells when combined with demineralized bone matrix or on an acellular scaffold for the treatment of non-union or avascular necrosis [64-66]. Importantly, the growing body of clinical evidence that supports the use of bone marrow derived stem cells, concentrated or expanded ex vivo, involves a wide variation of processing methods, concentration and time to aspiration. Such heterogeneity in methods hinders the true evaluation of the applications' efficacy [49, 67-69]. Additionally, the heterogeneity of culture expanded stem cells where the selection is not clonal and where the cells that adhere to tissue culture plastic may be variable in their phenotype. This therefore makes clonal culture very important, whereby the selection of an appropriate clone may be an option.

Implantation of foetal or adult stem cells into a critical size defect in rats has been shown to enhance fracture healing [48]. There may be additional advantages in differentiating the MSCs along the osteogenic and chondrogenic lineage prior to injection into the fracture site as it promoted endochondral ossification [70, 71]. The time of cell intervention is reported to be critical and a recent study showed that administration of MSCs into a critical size diaphyseal defect 7 days after injury, significantly reduced the rate of bony bridging when compared to immediate cell administration [72]. However, where a stem cell treatment is advocated for a delayed union, a delay of the administration of stem cells to the fracture site is unavoidable [73, 74]. In cases where delayed administration is unavoidable, it may be appropriate to debride and 'freshen up' the fracture site. In delayed and non-union, autologous bone marrow derived cells (bMSCs) have been used in multiple studies to enhance bone formation at the fracture site, leading to improved functional outcomes and healing as evidenced by radiographs.

The application of stem cells to the fracture site is reliant on a suitable carrier or scaffold. In the case of delayed and non-unions and in both osteoporotic and non-osteoporotic patients, a number of scaffolds have been investigated. These scaffolds can be autogenic or allogenic bone or synthetic bone graft substitute materials (BGS). Autograft remains the gold standard and has osteoinductive potential. Allograft and bone substitute materials are reported to be osteoconductive $[25,75]$. Combining stem cells with graft substitute materials may enhance their osteoinductive potential and improve bone fracture repair.

The use of culture expanded MSCs in combination with a BGS was investigated in the treatment of long-standing non-union of the tibia [76, 77]. Bajada et al. 2007 combined a pellet of autologous bone marrow stromal cells within a calcium sulphate scaffold prior to introduction into a tibial non-union in a patient. Eight weeks after surgery, the patient was able to fully bear weight on his leg, with clinical union and abundant callus evident [77]. Manassero et al investigated the potential of autologous MSCs combined with a resorbable Acropora Coral 
scaffold implanted into a critical defect site in sheep. After demonstrating that MSCs proliferated within the scaffold over a 7-day period, the scaffold and cell composite was implanted into sheep and a two-fold increase in bone formation was measured 6 months post-operatively. One scaffold was reported to have almost completely resorbed leading to full bone regeneration within the defect site [76].

Transplanted bMSCs are reported to survive and proliferate in the short term ( 2 weeks) when seeded onto porous silk scaffolds in a rat cranial defect model, but cell number has been shown to decrease in the longer term ( 8 weeks) where cell survival is reported to be poor [48, 78, 79]. In addition, loading scaffolds with growth factors (VEGF and BMP-2) can promote differentiation along both angiogenic and osteogenic lineages [78].

\subsection{Minimally manipulated stem cells in fracture repair}

Of the many factors that affect the in vivo outcome following stem cell intervention, the cell delivery method, source of cells and the mechano-biology of the fracture environment are considered the most significant. Cell delivery may be local or systemic. Hernigou et al (2005) seeded minimally manipulated autologous cells derived from bone marrow, directly at the fracture site during surgery. If successful, the use of minimally manipulated stem cells has several advantages over cultured stem cells, which are economical, convenient with limited regulatory implications. Hernigou et al (2005) employed the technique of aspirating autologous bone marrow (typically from the iliac crest), immediate centrifugation and implantation of the concentrated mononuclear cells into the defect site. This may be further augmented with the addition of bone substitutes. An alternative approach may be to use minimally manipulated adipose derived stem cells where fat tissue is taken during surgery, enzymatically treated, releasing stem cells, which are concentrated and reintroduced into the fracture site [74]. The number of MSCs has been shown to be low at around 1 in 100000 nucleated cells in a bone marrow aspirate and at this low concentration, the usefulness of stem cells is speculative. The usefulness of the bone marrow aspirate could therefore be due to cytokines and chemokine and not just the cells [80].

\section{Osteoporosis}

\subsection{Current treatments for osteoporosis}

Osteoporosis is defined as a "disease characterized by low bone mass and micro-architectural deterioration of bone tissue, leading to enhanced bone fragility and a consequent increase in fracture risk; and as such is an increasing medical and socioeconomic threat [81]. A patient with osteoporosis has an increased lifetime fracture risk of $40 \%$ [82-84]. The main feature of osteoporosis is a reduction in skeletal mass caused by an imbalance between bone resorption and bone formation [85]. Bisphosphonates are the common treatment for osteoporosis, and these drugs have been shown to reduce the risk of fracture, however they only prevent the resorption of bone rather than restore lost bone $[86,87]$. They have been shown to marginally increase bone mineral density. Their long-term use has raised concern of atypical sub-trochanteric fractures of the femur [88]. This may be associated with the failure of bone to remodel these micro-cracks due to the inactivation of the osteoclast which subsequently lead to fractures.

A number of drugs are in evaluation as both anabolic and anti-catabolic agents. Anti-sclerostin antibody and parathyroid hormone (PTH) together with its analogues. PTH 1-34 (teriparatide) and PTHrP analogues (abaloparatide), have been shown to have a dual anti-catabolic and anabolic effect. These agents have also been shown to act directly on the differentiation of stem cells promoting the formation of osteoblasts and bone formation $[73,78]$.

Anti-Sclerostin therapy has been shown to be effective at increasing bone density and strength in animal models with osteopenia and patients with osteoporosis. A number of studies have investigated the effect of anti-sclerostin on fracture repair and healing. Systemic administration of sclerostin antibody enhances bone repair in a criticalsized femoral defect in a rat model [89]. In an osteopenic closed fracture model in rats it was demonstrated that anti sclerostin increased bone mass, bone strength and bone formation at the fracture site [90]. These authors also showed that MSCs isolated from rats injected with anti sclerostin proliferated faster and expressed greater levels of ALP than cells isolated from non-treated rats. 
Both continuous and intermittent administration of PTH leads to increased bone turnover at trabecular and cortical sites. Unlike continuous dosing that results in increased osteoclast activation, pulsatile PTH administration results in increased trabecular bone volume. Intermittent PTH induces the activation of RUNX2, which drives the differentiation of stem cells down the osteoblastic lineage and it also maintains osteoblast maturity and thus has a role in increasing bone formation in osteoporosis [91-93]. Interestingly more recent studies have also started exploring the use of natural remedies such as Naringin to stimulate the differentiation of MSCs to bone [94, 95].

\subsection{Stem cell Therapy for treating osteoporosis}

Bone formation in osteoporotic patients appears to be compromised and one of the reasons may be that MSCs from post-menopausal women have a slower growth rate and lower osteogenic differentiation ability when compared to MSCs from pre-menopausal women [10, 96-98]. Impairment of bone formation combined with the increased fracture risk, suggests that fragility fractures in these patients are more susceptible to the formation of delayed or non-unions [40].

Examination of bone marrow from osteoporotic patients has been shown to have a significantly increased number of adipocytes when compared to a normal bone marrow stroma. According to Rodriguez et al, this preferential differentiation towards adipogenesis rather than osteogenesis is due to MSCs from post-menopausal patients synthesising 50\% less collagen I and 60\% less TGF- $\beta$ than MSCs from pre-menopausal women [97]. The role and inability of stem cells to form bone in osteoporotic individuals has therefore been highlighted in several studies.

A number of studies have investigated the use of MSCs to enhance bone formation in osteopenic/osteoporotic bone. Wang et al. injected MSCs embedded within a calcium alginate gel, into fractured femurs of ovariectomised (OVX) rabbits. After 2 months, an increase in bone apposition, trabecular thickness and bone stiffness was observed in the rabbits treated with MSCs [99]. Similar results were shown by Ocarino et al. 2010, when GFP labelled MSCs were injected into the femoral bone marrow cavity in OVX rats. Treated rats showed a significantly increased bone formation in the femur compared to the control group with the GFP labelled cells lining the surface of the newly formed bone [100].

The source of stem cell may be important. Umbilical cord blood-derived stem cells (UCB) have also recently generated tremendous interest in the orthopaedic field. UCB can be harvested non-invasively without any risk to the donor, while possessing a low immunogenic potential, giving them a diverse applicability in cell therapy. An et al, demonstrated a 30\% increase in bone mineral density (BMD) when human UBC-MSCs were injected in OVX mice after 4 and 8 weeks. They also observed increases in trabecular volume, number and thickness in OVX mice treated with hUB-MSCs [101].

Ye et al, transplanted autologous ADSCs in alginate in the femoral condyles of OVX rabbits, and found that it enhanced bone mass, increased cancellous bone formation and decreased bone loss at 8 weeks in comparison to the groups with only alginate transplanted in the condyles. Additionally, at 12 weeks, BMD reached $88 \%$ of the control non-stem cell treated group. Additionally, they also demonstrated that ADSCs in alginate composites in vitro positively induced a BMP signalling pathway that could favour osteogenesis and inhibit adipogenesis [102]. These studies suggest the potential use of stem cells in the treatment of osteoporosis.

\section{Systemic mobilisation of stem cells}

Systemic mobilisation of stem cells to the fracture site is dependent on the physiology of the host, which is associated with chemokines such as the SDF1/CXCR4 axis (Figure 1). An alternative and adjunct to the mobilisation of the stem cells from the host bone marrow may be to deliver stem cells intravenously. This route would still rely on the migration to the site of injury, which would be governed by the release of chemoattractant factors $[4,74,103]$. The delivery of cells to the injury site is a critical issue with cell-based therapies. 

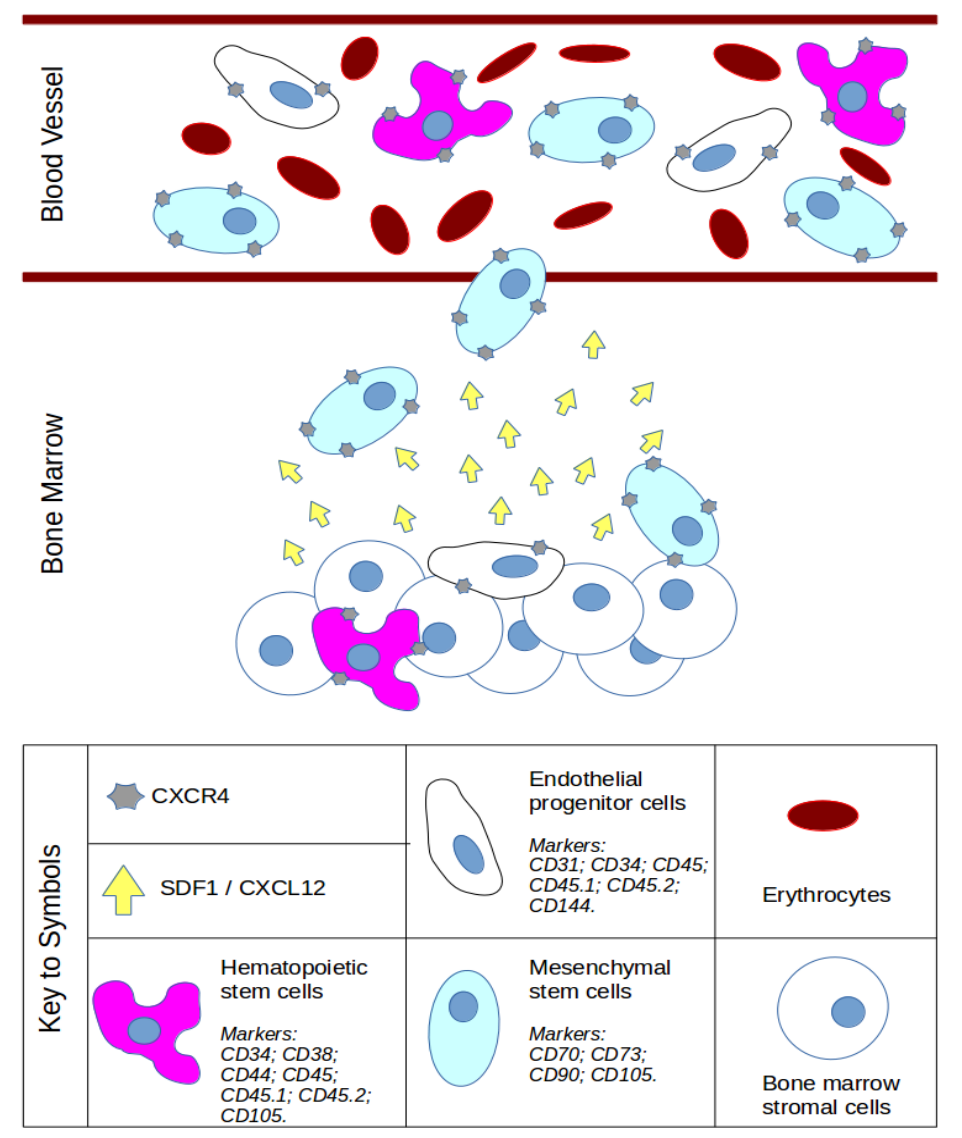

Figure 1: The mobilisation mechanism of cells from their niche and possible role for circulating stem cells in fracture healing. Stromal cell-derived factor 1 (SDF-1/CXCL12) is strongly expressed at the injury sire by cells including bone marrow stromal cells. SDF-1 along with other chemokines, mediates cell migration towards the site of injury through interaction with the CXCR4 receptor. Multipotent cells expressing CXCR4 are shown, and markers for their identification are listed. Administration of AMD3100 (Plerixafor) blocks SDF-1/CXCR4 binding and can therefore be used to increase mobilisation of multipotent cells into the bloodstream.

For stem cells to regenerate any tissue, they must first migrate to the site of injury site and this is influenced by multiple factors including age and passage number of cells, culture conditions and the delivery method $[104,105]$. Genetically manipulating stem cells can increase their homing ability and can systemically deliver therapeutic proteins into circulation [103]. Lien et al. systemically injected murine MSC-like cells (C3H10T1/2) into glucocorticoid-induced osteoporotic mice [106]. Cells were transduced with CXCR4 and Cbfa-1 that increase the migration and osteogenic differentiation of cells respectively. 4 weeks post-transplantation a significant increase in bone mineral density (BMD) was observed in the femora of osteoporotic mice [106]. RANK-Fc blocks osteoclast differentiation [107] and improves BMD in ovariectomised mice after 4 weeks of introduction of cells transfected with RANK-Fc [108]. Modifying cells to express RANK-Fc and CXCR4 also improve stem cell homing while enhancing bone formation in comparison to using RANK-Fc on its own and this resulted into significant protection against OVX-induced bone loss [109]. Additionally, a more recent study by Huang et al, 2016 found that systemic administration of allogenic MSCs from OVX rats does not prevent osteoporotic bone loss in ovariectomised rats. They found no significant difference in micro-Ct, mechanical testing and histology results between rats receiving sham injections and repeated doses of allogeneic stem cells [110]. This could be because the migration and osteogenic differentiation of stem cells from osteopenic rats is compromised and therefore injecting this type of cells may not improve bone formation in osteoporosis. 
The processes of cell recruitment, migration and homing to the fracture site are essential for the inflammatory process, neovascularization, chondrogenesis, osteogenesis and ultimately bone formation in normal bone repair. Stem cells navigate from the periosteum and bone marrow, and may also be recruited from the circulation and distant bone marrow. Mobilisation and migration requires stem cells to enter and exit the vasculature. A process similar to extravasation used by leukocytes to exit the vasculature is believed to occur.

The work of Pitchford et al, 2009 showed that mobilization of EPCs, MSCs and HSCs was dependent upon different cytokines [111]. MSC mobilization was detected when the AMD3100 (Plerixafor), an antagonist to CXCR4, was administered to mice pretreated with VEGF, but not G-CSF, whereas VEGF pretreatment enhanced EPC mobilization whilst GCSF pretreatment enhance the mobilization of HSCs without the addition of the CXCR4 antagonist[111]. The CXCR4 and CXCL12 interaction is thought to be important in mobilization. The manipulation of the stem cell niche using different cytokines has led to the proposition that circulating stem cells could be controlled by administering different cytokines allowing the cells to be released and home to the fracture site thus enhancing repair. Rapp and co-workers showed strong expression of SDF-1 by nearly all cells near the osteotomy, indicating that SDF-1 may mediate cell migration to the injury site. When they created a femoral osteotomy and injected stem cells systemically into mice, they saw more bone in the callus compared to sham control group. However, bending stiffness of the callus had not improved significantly compared to the control. The role of SDF-1 in fracture healing has also been highlighted in a study by Ho and co-workers, 2014. Stem cells transfected with SDF-1 were shown to improve bone formation in femoral defects in rats compared to those that received untransfected MSCs, due to SDF-1 mediating the migration of stem cells to the fracture site [112].

AMD3100, an antagonist of CXCR4, when given to rats for 3 days after fracture resulted in an increase in the number of circulating MSCs, HSCs, and EPCs. In mice the migration of stem cells from their niche can be further promoted by the injection of cytokines such as IGF, FGF and GCSF. Several studies have outlined the positive effect of AMD-3100 administration on bone growth following delivery of a bone lesion in an animal model [113, 114]. Mobilization of MSCs from bone marrow after AMD-3100 administration resulted in a significant augmentation of bone formation when it was co-administrated with IGF-1 [115]. HSC mobilization by G-CSF has been investigated in a phase II clinical trial following tibial osteotomy. In this study, patients who received G-CSF infusion for 3 consecutive days and 4 hours before surgery showed increased osteointegration within bone graft when compared to the untreated control patient group [116]. The timing of stem cell mobilisation is crucial especially if AMD3100 is to be used as this could prevent homing of the stem cells to the SDF1 released at the fracture site. Circulating stem cells may be captured in the lungs and the spleen and this may present a problem with the injection of cultured expanded cells which are larger than cells released from the stem cell niche [117119].

\section{Minimally Manipulated Cell Therapy}

The human bone marrow is made up of multiple cell subpopulations that could potentially contribute to injury repair. Besides haematopoietic stem cells and MSCs, bone marrow also contains other cell types such as adventitial reticular cells, vascular pericytes, bone marrow fibroblasts and bone lining cells. Some of these cells possess the ability to self-renew, maintain genetic and/or epigenetic profiles that make them more programmable in vivo and retain sufficient proliferative, secretory and differentiation potentials to repair a specific tissue [120]. Many studies have focused on the use of stem cells following culture expansion and during this time, adherent MSCs are the primary cell types that overgrow and adapt to the in vitro culture environment. Cell expansion and culture adaptation may come at the expense of altered biological and secretory features that distinguish MSCs from their in vivo counterparts [121]. For this reason and also due to patients often having to undergo an additional procedure to obtain the bone marrow aspirate, the increased time, costs and regulatory requirements, minimally manipulated cells obtained at the time of surgery offer a number of advantages over using expanded cells. The mononuclear cell fraction isolated from bone marrow aspirate or subcutaneous adipose tissue can be obtained using density gradient centrifugation and/or digestion methods during surgery. This cell population is often termed 'minimally manipulated' and may represent a novel strategy for enhancing tissue repair and regeneration. Preclinical as well as clinical studies have demonstrated that the application of minimally manipulated mononuclear cells possess therapeutic repair capabilities. 
6. Conclusion

This review has investigated the way in which stem cell therapy may be used to enhance bone formation during fracture healing. Presently, delayed- and non-unions are a considerable economic burden with high patient morbidity and stem cell treatment may provide a method of treatment particularly in osteoporotic patients. Preclinical studies have shown that cell therapy can be further enhances when combined with scaffolds, growth factors, cytokines and chemokines. However, the potential of stem cell treatment in fracture healing remains uncertain as more clinical trials are required to investigate these novel treatment strategies in patients with osteoporotic fractures.

\section{References}

[1]. $\quad$ Friedenstein AJ, Piatetzky S, II, Petrakova KV. Osteogenesis in transplants of bone marrow cells. J Embryol Exp Morphol. 1966;16(3):381-90.

[2]. Ashman O, Phillips AM. Treatment of non-unions with bone defects: which option and why? Injury. 2013;44 Suppl 1:S43-5.

[3]. Gaston M, Simpson A. Inhibition of fracture healing. Journal of Bone \& Joint Surgery, British Volume. 2007;89(12):1553-60.

[4]. Gómez-Barrena E, Rosset P, Lozano D, et al. Bone fracture healing: Cell therapy in delayed unions and nonunions. Bone. 2015;70(Supplement C):93-101.

[5]. Wiss DA, Stetson WB. Tibial nonunion: treatment alternatives. Journal of the American Academy of Orthopaedic Surgeons. 1996;4(5):249-57.

[6]. Somford MP, van den Bekerom MP, Kloen P. Operative treatment for femoral shaft nonunions, a systematic review of the literature. Strategies in Trauma and Limb Reconstruction. 2013;8(2):77-88.

[7]. Mechrefe AP, Koh EY, Trafton PG, DiGiovanni CW. Tibial nonunion. Foot and ankle clinics. 2006;11(1):1-18.

[8]. Johnell $\mathrm{O}$, Kanis J. An estimate of the worldwide prevalence and disability associated with osteoporotic fractures. Osteoporosis international. 2006;17(12):1726-33.

[9]. Kim M, Kim C, Choi YS, et al. Age-related alterations in mesenchymal stem cells related to shift in differentiation from osteogenic to adipogenic potential: implication to age-associated bone diseases and defects. Mech Ageing Dev. 2012;133(5):215-25.

[10]. Pino AM, Rosen CJ, Rodriguez JP. In osteoporosis, differentiation of mesenchymal stem cells (MSCs) improves bone marrow adipogenesis. Biol Res. 2012;45(3):279-87.

[11]. Cornell CN. Internal fracture fixation in patients with osteoporosis. Journal of the American Academy of Orthopaedic Surgeons. 2003;11(2):109-19.

[12]. Tejwani NC, Guerado E. Improving fixation of the osteoporotic fracture: the role of locked plating. Journal of orthopaedic trauma. 2011;25:S56-S60.

[13]. Rosset P, Deschaseaux F, Layrolle P. Cell therapy for bone repair. Orthop Traumatol Surg Res. 2014;100(1 Suppl):S107-12.

[14]. Fazzalari NL. Bone fracture and bone fracture repair. Osteoporos Int. 2011;22(6):2003-6.

[15]. Shapiro F. Bone development and its relation to fracture repair. The role of mesenchymal osteoblasts and surface osteoblasts. Eur Cell Mater. 2008;15:53-76.

[16]. Sfeir C, Ho L, Doll BA, Azari K, Hollinger JO. Fracture repair. Bone Regeneration and Repair: Springer; 2005. p. 21-44.

[17]. Kraus T, Zwick EB, Svehlik M, Linhart WE. Lengthening of the Midfoot in a Case of Lowerextremity Hemimelia. Journal of the American Podiatric Medical Association. 2011;101(5):456-61.

[18]. Deschaseaux F, Sensebe L, Heymann D. Mechanisms of bone repair and regeneration. Trends Mol Med. 2009;15(9):417-29.

[19]. Echeverri LF, Herrero MA, Lopez JM, Oleaga G. Early stages of bone fracture healing: formation of a fibrin-collagen scaffold in the fracture hematoma. Bull Math Biol. 2015;77(1):156-83. [20]. Schmidt-Bleek K, Schell H, Schulz N, et al. Inflammatory phase of bone healing initiates the regenerative healing cascade. Cell Tissue Res. 2012;347(3):567-73. 
[21]. Allori AC, Sailon AM, Pan JH, Warren SM. Biological basis of bone formation, remodeling, and repair-part III: biomechanical forces. Tissue Engineering Part B: Reviews. 2008;14(3):285-93.

[22]. Schindeler $A, M c D o n a l d ~ M M, B o k k o P$, Little $D G$. Bone remodeling during fracture repair: The cellular picture. Semin Cell Dev Biol. 2008;19(5):459-66.

[23]. Ito H. Chemokines in mesenchymal stem cell therapy for bon erepair: a novel concept of recruiting mesenchymal stem cells and the possible cell sources. Modern Rheumatology.

2011;21:113 - 21.

[24]. Dimitriou R, Tsiridis E, Giannoudis PV. Current concepts of molecular aspects of bone healing. Injury. 2005;36(12):1392-404.

[25]. Giannoudis PV, Dinopoulos H, Tsiridis E. Bone substitutes: an update. Injury. 2005;36(3):S20-S7.

[26]. Bai Y, Li P, Yin G, et al. BMP-2, VEGF and bFGF synergistically promote the osteogenic differentiation of rat bone marrow-derived mesenchymal stem cells. Biotechnol Lett.

2013;35(3):301-8.

[27]. Wang $X$, Wang $Y$, Gou W, et al. Role of mesenchymal stem cells in bone regeneration and fracture repair: a review. International orthopaedics. 2013;37(12):2491-8.

[28]. Ode A, Kopf J, Kurtz A, et al. CD73 and CD29 concurrently mediate the mechanically induced decrease of migratory capacity of mesenchymal stromal cells. Eur Cell Mater. 2011;22:2642.

[29]. Giannoudis P, Panteli M, Calori G. Bone Healing: The Diamond Concept. In: Bentley G, editor. European Instructional Lectures. European Instructional Lectures. 14: Springer Berlin Heidelberg; 2014. p. 3-16.

[30]. Calori GM, Giannoudis PV. Enhancement of fracture healing with the diamond concept: the role of the biological chamber. Injury. 2011;42(11):1191-3.

[31]. Colnot C. Skeletal cell fate decisions within periosteum and bone marrow during bone regeneration. Journal of Bone and Mineral Research. 2009;24(2):274-82.

[32]. Malizos KN, Papatheodorou LK. The healing potential of the periosteum molecular aspects. Injury. 2005;36 Suppl 3:S13-9.

[33]. Thompson WR, Rubin CT, Rubin J. Mechanical regulation of signaling pathways in bone. Gene. 2012;503(2):179-93.

[34]. Roberts SJ, van Gastel N, Carmeliet G, Luyten FP. Uncovering the periosteum for skeletal regeneration: The stem cell that lies beneath. Bone. 2015;70:10-8.

[35]. Granero-Molto F, Weis JA, Miga MI, et al. Regenerative effects of transplanted mesenchymal stem cells in fracture healing. Stem cells. 2009;27(8):1887 - 98.

[36]. Keramaris NC, Kaptanis S, Moss HL, et al. Endothelial progenitor cells (EPCS) and mesenchymal stem cells (MSCs) in bone healing. Curr Stem Cell Res Ther. 2012;7(4):293-301.

[37]. Bielby R, Jones E, McGonagle D. The role of mesenchymal stem cells in maintenance and repair of bone. Injury. 2007;38(1):S26-S32.

[38]. Shah AD, Shoback D, Lewiecki EM. Sclerostin inhibition: a novel therapeutic approach in the treatment of osteoporosis. Int J Womens Health. 2015;7:565-80.

[39]. Tapp H, Hanley EN, Patt JC, Gruber HE. Adipose-derived stem cells: characterization and current application in orthopaedic tissue repair. Experimental biology and medicine. 2009;234(1):19.

[40]. Gómez-Barrena E, Rosset P, Lozano D, et al. Bone fracture healing: Cell therapy in delayed unions and nonunions. Bone. 2015;70:93-101.

[41]. Amini AR, Laurencin CT, Nukavarapu SP. Bone tissue engineering: recent advances and challenges. Crit Rev Biomed Eng. 2012;40(5):363-408.

[42]. Abou-Khalil R, Yang F, Lieu S, et al. Role of muscle stem cells during skeletal regeneration. Stem Cells. 2015;33(5):1501-11.

[43]. Murphy WL, McDevitt TC, Engler AJ. Materials as stem cell regulators. Nat Mater. 2014;13(6):547-57. 
[44]. Potier E, Noailly J, Ito K. Directing bone marrow-derived stromal cell function with mechanics. J Biomech. 2010;43(5):807-17.

[45]. MacQueen L, Sun Y, Simmons CA. Mesenchymal stem cell mechanobiology and emerging experimental platforms. Journal of The Royal Society Interface. 2013;10(84):20130179.

[46]. Wang YK, Chen CS. Cell adhesion and mechanical stimulation in the regulation of mesenchymal stem cell differentiation. J Cell Mol Med. 2013;17(7):823-32.

[47]. Histing $\mathrm{T}$, Garcia $\mathrm{P}$, Holstein $\mathrm{JH}$, et al. Small animal bone healing models: standards, tips, and pitfalls results of a consensus meeting. Bone. 2011;49(4):591-9.

[48]. Dupont KM, Sharma K, Stevens HY, et al. Human stem cell delivery for treatment of large segmental bone defects. Proceedings of the National Academy of Sciences. 2010;107(8):3305-10.

[49]. Khosla S, Westendorf JJ, Mödder UI. Concise Review: Insights from Normal Bone Remodeling and Stem Cell-Based Therapies for Bone Repair. Stem Cells. 2010;28(12):2124-8.

[50]. Dawson JI, Kanczler J, Tare R, Kassem M, Oreffo RO. Concise review: bridging the gap: bone regeneration using skeletal stem cell-based strategies - where are we now? Stem Cells. 2014;32(1):35-44.

[51]. Grayson WL, Bunnell BA, Martin E, et al. Stromal cells and stem cells in clinical bone regeneration. Nat Rev Endocrinol. 2015;11(3):140-50.

[52]. Brennan M, Davaine JM, Layrolle P. Pre-vascularization of bone tissue-engineered constructs. Stem Cell Res Ther. 2013;4(4):96.

[53]. Hicok KC, Du Laney TV, Zhou YS, et al. Human adipose-derived adult stem cells produce osteoid in vivo. Tissue Eng. 2004;10(3-4):371-80.

[54]. Fraser JK, Wulur I, Alfonso Z, Hedrick MH. Fat tissue: an underappreciated source of stem cells for biotechnology. Trends Biotechnol. 2006;24(4):150-4.

[55]. Cui L, Liu B, Liu G, et al. Repair of cranial bone defects with adipose derived stem cells and coral scaffold in a canine model. Biomaterials. 2007;28(36):5477-86.

[56]. Levi B, James AW, Nelson ER, et al. Human adipose derived stromal cells heal critical size mouse calvarial defects. PLoS One. 2010;5(6):e11177.

[57]. Mesimaki K, Lindroos B, Tornwall J, et al. Novel maxillary reconstruction with ectopic bone formation by GMP adipose stem cells. Int J Oral Maxillofac Surg. 2009;38(3):201-9.

[58]. Lendeckel S, Jodicke A, Christophis $P$, et al. Autologous stem cells (adipose) and fibrin glue used to treat widespread traumatic calvarial defects: case report. J Craniomaxillofac Surg. 2004;32(6):370-3.

[59]. Thesleff T, Lehtimaki K, Niskakangas T, et al. Cranioplasty with adipose-derived stem cells and biomaterial: a novel method for cranial reconstruction. Neurosurgery. 2011;68(6):1535-40.

[60]. Unger RE, Dohle E, Kirkpatrick CJ. Improving vascularization of engineered bone through the generation of pro-angiogenic effects in co-culture systems. Adv Drug Deliv Rev. 2015.

[61]. Li R, Stewart DJ, von Schroeder HP, Mackinnon ES, Schemitsch EH. Effect of cell-based VEGF gene therapy on healing of a segmental bone defect. Journal of Orthopaedic Research. 2009;27(1):8-14.

[62]. van Gastel N, Torrekens S, Roberts SJ, et al. Engineering vascularized bone: osteogenic and proangiogenic potential of murine periosteal cells. Stem Cells. 2012;30(11):2460-71.

[63]. Stegen S, van Gastel N, Carmeliet G. Bringing new life to damaged bone: the importance of angiogenesis in bone repair and regeneration. Bone. 2015;70:19-27.

[64]. Kawate $\mathrm{K}$, Yajima H, Ohgushi $\mathrm{H}$, et al. Tissue-engineered approach for the treatment of steroid-induced osteonecrosis of the femoral head: transplantation of autologous mesenchymal stem cells cultured with beta-tricalcium phosphate ceramics and free vascularized fibula. Artif Organs. 2006;30(12):960-2.

[65]. Muller I, Vaegler M, Holzwarth C, et al. Secretion of angiogenic proteins by human multipotent mesenchymal stromal cells and their clinical potential in the treatment of avascular osteonecrosis. Leukemia. 2008;22(11):2054-61. 
[66]. Marcacci M, Kon E, Moukhachev V, et al. Stem cells associated with macroporous bioceramics for long bone repair: 6- to 7-year outcome of a pilot clinical study. Tissue Eng. 2007;13(5):947-55.

[67]. MacCallum CJ. Reporting animal studies: good science and a duty of care. PLoS Biol. 2010;8(6):e1000413.

[68]. Stewart SK, Bennett PM, Stapley SA, et al. Pre-clinical evaluation of therapies to prevent or treat bone non-union: a systematic review protocol. Systematic reviews. 2015;4(1):1.

[69]. Prayle AP, Hurley MN, Smyth AR. Compliance with mandatory reporting of clinical trial results on ClinicalTrials.gov: cross sectional study2012 2012-01-03 23:34:52.

[70]. Harada N, Watanabe $\mathrm{Y}$, Sato $\mathrm{K}$, et al. Bone regeneration in a massive rat femur defect through endochondral ossification achieved with chondrogenically differentiated MSCs in a degradable scaffold. Biomaterials. 2014;35(27):7800-10.

[71]. Kim SJ, Shin YW, Yang KH, et al. A multi-center, randomized, clinical study to compare the effect and safety of autologous cultured osteoblast(Ossron) injection to treat fractures. BMC Musculoskelet Disord. 2009;10:20.

[72]. Dosier CR, Uhrig BA, Willett NJ, et al. Effect of cell origin and timing of delivery for stem cell-based bone tissue engineering using biologically functionalized hydrogels. Tissue Eng Part $A$. 2015;21(1-2):156-65.

[73]. Bhargava R, Sankhla S, Gupta A, Changani R, Gagal K. Percutaneous autologus bone marrow injection in the treatment of delayed or nonunion. Indian J Orthop. 2007;41(1):67-71.

[74]. Hernigou P, Poignard A, Manicom O, Mathieu G, Rouard H. The use of percutaneous autologous bone marrow transplantation in nonunion and avascular necrosis of bone. Bone \& Joint Journal. 2005;87(7):896-902.

[75]. Kao ST, Scott DD. A review of bone substitutes. Oral and maxillofacial surgery clinics of North America. 2007;19(4):513-21.

[76]. Manassero $M$, Viateau V, Deschepper $M$, et al. Bone regeneration in sheep using acropora coral, a natural resorbable scaffold, and autologous mesenchymal stem cells. Tissue Engineering Part A. 2013;19(13-14):1554-63.

[77]. Bajada S, Harrison P, Ashton B, et al. Successful treatment of refractory tibial nonunion using calcium sulphate and bone marrow stromal cell implantation. Bone \& Joint Journal. 2007;89(10):1382-6.

[78]. Zhang W, Zhu C, Ye D, et al. Porous Silk Scaffolds for Delivery of Growth Factors and Stem Cells to Enhance Bone Regeneration. 2014.

[79]. Brennan MA, Renaud A, Amiaud J, et al. Pre-clinical studies of bone regeneration with human bone marrow stromal cells and biphasic calcium phosphate. Stem Cell Res Ther.

2014;5(5):114.

[80]. Wexler SA, Donaldson C, Denning-Kendall P, et al. Adult bone marrow is a rich source of human mesenchymal 'stem'cells but umbilical cord and mobilized adult blood are not. British journal of haematology. 2003;121(2):368-74.

[81]. Kanis JA, Melton L, Christiansen C, Johnston CC, Khaltaev N. The diagnosis of osteoporosis. Journal of bone and mineral research. 1994;9(8):1137-41.

[82]. Rachner TD, Khosla S, Hofbauer LC. Osteoporosis: now and the future. The Lancet. 2011;377(9773):1276-87.

[83]. Woolf AD, Pfleger B. Burden of major musculoskeletal conditions. Bulletin of the World Health Organization. 2003;81(9):646-56.

[84]. Braithwaite RS, Col NF, Wong JB. Estimating hip fracture morbidity, mortality and costs. Journal of the American Geriatrics Society. 2003;51(3):364-70.

[85]. Manolagas SC, Jilka RL. Bone Marrow, Cytokines, and Bone Remodeling - Emerging Insights into the Pathophysiology of Osteoporosis. New England Journal of Medicine.

1995;332(5):305-11. 
[86]. Antebi B, Pelled G, Gazit D. Stem cell therapy for osteoporosis. Current osteoporosis reports. 2014;12(1):41-7.

[87]. Chapurlat RD. Odanacatib: a review of its potential in the management of osteoporosis in postmenopausal women. Therapeutic advances in musculoskeletal disease.

2015:1759720X15580903.

[88]. Isaacs JD, Shidiak L, Harris IA, Szomor ZL. Femoral insufficiency fractures associated with prolonged bisphosphonate therapy. Clin Orthop Relat Res. 2010;468(12):3384-92.

[89]. Virk MS, Alaee F, Tang $\mathrm{H}$, et al. Systemic administration of sclerostin antibody enhances bone repair in a critical-sized femoral defect in a rat model. The Journal of bone and joint surgery American volume. 2013;95(8):694.

[90]. Liu Y, Rui Y, Cheng TY, et al. Effects of sclerostin antibody on the healing of femoral fractures in ovariectomised rats. Calcified tissue international. 2016;98(3):263-74.

[91]. Powell WF, Jr., Barry KJ, Tulum I, et al. Targeted ablation of the PTH/PTHrP receptor in osteocytes impairs bone structure and homeostatic calcemic responses. J Endocrinol.

2011;209(1):21-32.

[92]. Mason JJ, Williams BO. SOST and DKK: antagonists of LRP family signaling as targets for treating bone disease. Journal of osteoporosis. 2010;2010.

[93]. Osagie-Clouard L, Sanghani A, Coathup M, et al. Parathyroid hormone 1-34 and skeletal anabolic action: The use of parathyroid hormone in bone formation. Bone Joint Res. 2017;6(1):1421.

[94]. Yu G-y, Zheng G-z, Chang B, et al. Naringin stimulates osteogenic differentiation of rat bone marrow stromal cells via activation of the notch signaling pathway. Stem cells international. 2016;2016.

[95]. Wang $\mathrm{H}$, Li C, Li J, et al. Naringin enhances osteogenic differentiation through the activation of ERK signaling in human bone marrow mesenchymal stem cells. Iranian journal of basic medical sciences. 2017;20(4):408.

[96]. Rodriguez JP, Garat S, Gajardo H, Pino AM, Seitz G. Abnormal osteogenesis in osteoporotic patients is reflected by altered mesenchymal stem cells dynamics. J Cell Biochem. 1999;75(3):414-

23.

[97]. Rodriguez JP, Montecinos L, Rios S, Reyes P, Martinez J. Mesenchymal stem cells from osteoporotic patients produce a type I collagen-deficient extracellular matrix favoring adipogenic differentiation. J Cell Biochem. 2000;79(4):557-65.

[98]. Nuttall ME, Gimble JM. Controlling the balance between osteoblastogenesis and adipogenesis and the consequent therapeutic implications. Current opinion in pharmacology. 2004;4(3):290-4.

[99]. Wang Z, Goh J, Das De S, et al. Efficacy of bone marrow-derived stem cells in strengthening osteoporotic bone in a rabbit model. Tissue Eng. 2006;12(7):1753-61.

[100]. Ocarino Nde M, Boeloni JN, Jorgetti V, et al. Intra-bone marrow injection of mesenchymal stem cells improves the femur bone mass of osteoporotic female rats. Connect Tissue Res.

2010;51(6):426-33.

[101]. An JH, Park H, Song JA, et al. Transplantation of human umbilical cord blood-derived mesenchymal stem cells or their conditioned medium prevents bone loss in ovariectomized nude mice. Tissue Eng Part A. 2013;19(5-6):685-96.

[102]. Ye X, Zhang P, Xue S, et al. Adipose-derived stem cells alleviate osteoporosis by enchancing osteogenesis and inhibiting adipogenesis in a rabbit model. Cytotherapy. 2014;16(12):1643-55.

[103]. Sanghani-Kerai A, Coathup M, Samazideh S, et al. Osteoporosis and ageing affects the migration of stem cells and this is ameliorated by transfection with CXCR4. Bone and Joint Research. 2017;6(6):358-65.

[104]. Sohni A, Verfaillie CM. Mesenchymal stem cells migration homing and tracking. Stem cells international. 2013;2013. 
[105]. Myers TJ, Yan Y, Granero-Molto F, et al. Systemically delivered insulin-like growth factor-I enhances mesenchymal stem cell-dependent fracture healing. Growth Factors. 2012;30(4):230-41.

[106]. Lien CY, Chih-Yuan Ho K, Lee OK, Blunn GW, Su Y. Restoration of Bone Mass and Strength in Glucocorticoid-Treated Mice by Systemic Transplantation of CXCR4 and Cbfa-1 Co-Expressing Mesenchymal Stem Cells. Journal of Bone and Mineral Research. 2009;24(5):837-48.

[107]. Hsu H, Lacey DL, Dunstan CR, et al. Tumor necrosis factor receptor family member RANK mediates osteoclast differentiation and activation induced by osteoprotegerin ligand. Proc Natl Acad Sci U S A. 1999;96(7):3540-5.

[108]. Kim D, Cho SW, Her SJ, et al. Retrovirus-mediated gene transfer of receptor activator of nuclear factor-kappaB-Fc prevents bone loss in ovariectomized mice. Stem Cells. 2006;24(7):1798805.

[109]. Cho SW, Sun HJ, Yang J-Y, et al. Transplantation of mesenchymal stem cells overexpressing RANK-Fc or CXCR4 prevents bone loss in ovariectomized mice. Molecular Therapy. 2009;17(11):1979-87.

[110]. Huang S, Xu L, Sun Y, et al. Systemic Administration of Allogeneic Mesenchymal Stem Cells Does Not Halt Osteoporotic Bone Loss in Ovariectomized Rats. PLOS ONE. 2016;11(10):e0163131.

[111]. Pitchford SC, Furze RC, Jones CP, Wengner AM, Rankin SM. Differential mobilization of subsets of progenitor cells from the bone marrow. Cell stem cell. 2009;4(1):62-72.

[112]. Ho C-Y, Sanghani A, Hua J, et al. Mesenchymal stem cells with increased stromal cellderived factor 1 expression enhanced fracture healing. Tissue Engineering Part A. 2014;21(3-4):594602.

[113]. Toupadakis CA, Granick JL, Sagy M, et al. Mobilization of endogenous stem cell populations enhances fracture healing in a murine femoral fracture model. Cytotherapy. 2013;15(9):1136-47.

[114]. Toupadakis CA, Wong A, Genetos DC, et al. Long-term administration of AMD3100, an antagonist of SDF-1/CXCR4 signaling, alters fracture repair. Journal of Orthopaedic Research. 2012;30(11):1853-9.

[115]. Kumar S, Ponnazhagan S. Mobilization of bone marrow mesenchymal stem cells in vivo augments bone healing in a mouse model of segmental bone defect. Bone. 2012;50(4):1012-8.

[116]. Marmotti A, Castoldi F, Rossi R, et al. Bone marrow-derived cell mobilization by G-CSF to enhance osseointegration of bone substitute in high tibial osteotomy. Knee Surgery, Sports Traumatology, Arthroscopy. 2013;21(1):237-48.

[117]. Gao J, Dennis JE, Muzic RF, Lundberg M, Caplan Al. The dynamic in vivo distribution of bone marrow-derived mesenchymal stem cells after infusion. Cells Tissues Organs. 2001;169(1):1220.

[118]. Fischer UM, Harting MT, Jimenez F, et al. Pulmonary passage is a major obstacle for intravenous stem cell delivery: the pulmonary first-pass effect. Stem cells and development. 2009;18(5):683-92.

[119]. Schrepfer S, Deuse T, Reichenspurner H, et al., editors. Stem cell transplantation: the lung barrier. Transplantation proceedings; 2007: Elsevier.

[120]. Misra K, Sabaawy HE. Minimally manipulated autologous adherent bone marrow cells (ABMCs): a promising cell therapy of spinal cord injury. Neural Regeneration Research. 2015;10(7):1058-60.

[121]. Prockop DJ. Repair of Tissues by Adult Stem/Progenitor Cells (MSCs): Controversies, Myths, and Changing Paradigms. Molecular Therapy. 2009;17(6):939-46. 